\title{
Teniposide (VM-26) in Patients with Advanced Refractory Ovarian Cancer: a Phase II Study of the Netherlands Joint Study Group for Ovarian Cancer
}

\author{
M.E.L. VAN DER BURG, ${ }^{*}$ W.W. TEN BOKKEL HUININK, $†$ R. VRIESENDORP $;+$ A.T. VAN \\ OOSTEROM,§ J.P. NEIJT,\| J.B. VERMORKEN, $\|$ W.L.J. VAN PUTTEN** and A. KOOIMAN††
}

*Department of Medical Oncology, Rotterdam Cancer Institute, Rntterdam, The Netherlands, †Department of Medical Oncology, Netherlands Cancer Institute, Amsterdam, The Netherlands, †Department of Oncology, State University Hospital, Groningen, The Netherlands, §Department of Clinical Oncology, State University Hospital, Leiden, The Netherlands, \|Department of Oncology, State University Hospital, Utrecht, The Netherlands, IDepartment of Medical Oncology, Free University Hospital, Amsterdam, The Netherlands, ${ }^{* *}$ Department of Statistics, Rotterdam Cancer Institute, Rotterdam, The Netherlands and ++ Data Manager, Rotterdam Cancer Institute, Rotterdam, The Netherlands

\begin{abstract}
In 23 evaluable patients with advanced ovarian epithelial cancer refractory to combination therapy with cisplatin and an alkylating agent, teniposide (VM-26) was administered as a short-term i.v. infusion at a dose of $100 \mathrm{mg} / \mathrm{m}^{2}$ on days 1 and 2 , every 3 weeks. Toxicity was moderate and comparable to the pattern known from other studies. No objective response has been observed, showing that teniposide is not active as second-line therapy in this disease.
\end{abstract}

\section{INTRODUCTION}

THE PROGNOSIS of patients with advanced epithelial ovarian cancer has been improved with the incorporation of cisplatin in combination chemotherapy regimens $[1,2]$. However, the major disadvantage of cisplatin-containing combination therapy is the considerable side effects in terms of nephro-, otoand especially neurotoxicity. This may lead to premature discontinuation of treatment. Hence, there is a need for active, but less toxic drugs. Teniposide (VM-26) has been suggested to be such an agent. So far, conflicting results with respect to the activity of VM-26 have been reported [3-5].

This is a report of a phase II study of VM-26 used in a 2-day schedule, given every 3 weeks to patients with advanced ovarian carcinoma refractory to combination therapy including cisplatin and an alkylating agent.

\section{MATERIALS AND METHODS}

Twenty-four patients with FIGO stage III-IV ovarian cancer were entered in the study. Patient

Accepted 20 January 1987

Address for correspondence: M.E.L. van der Burg, Department of Medical Oncology, Rotterdam Cancer Institute, Groene Hilledijk 301, 3075 EA Rotterdam, The Netherlands. eligibility criteria included histologically proven epithelial ovarian cancer, resistance to combination therapy including cisplatin and an alkylating agent, measurable and progressive disease, age $<70$ years, Karnofsky index $>70$, leucocytes $>3.0 \times 10^{9} / 1$., platelets $>75 \times 10^{9} / 1$., creatinine $<120 \mu \mathrm{mol} / \mathrm{l}$. and no chemotherapy or radiotherapy for at least 4 weeks prior to entry in the study.

Pretreatment studies included history and physical examination, complete blood counts, a 12-channel biochemical screen, chest film and CT scan or echoscopy. Treatment consisted of VM-26 $100 \mathrm{mg} /$ $\mathrm{m}^{2} /$ day on days 1 and 2 , once every 3 weeks. Infusion time varied from 30 to $60 \mathrm{~min}$. Patients were evaluable for toxicity if they had completed one treatment cycle and for response after two cycles. Responses were defined according to the WHO response criteria for measurable and evaluable disease [6]. Early death due to progressive malignant disease was evaluable as treatment failure, i.e. progression.

The patients' characteristics were: age 43-70 (median 58), Karnofsky index 70-100 (median $90)$, preceding treatment regimens $1-5$ (median 2 ), preceding drugs $2-8$ (median 4 ). 


\section{RESULTS}

Of 24 patients, one patient was inevaluable because she refused treatment after registration. Twenty-three patients were evaluable. Two patients died before the start of the second cycle due to progressive disease. After a median of three treatment cycles with VM-26 (range 2-17) no objective response was observed. Nine patients (42\%) had stable disease for a median duration of 4 months (range 3-17 months). The remaining 12 patients showed progressive disease. The median overall survival was 5 months (range $3-36$ months).

Haematologic toxicity was moderate. Treatment was postponed by $1-3$ weeks in eight patients. The median leucocyte nadir was $2.4 \times 10^{9} / 1$. (range $0.8-6.5)$, the median platelet nadir was $137 \times 10^{9} / 1$. (range 25-378). One patient needed platelet transfusion. The median nadir of haemoglobin during treatment was $5.8 \mathrm{mmol} / \mathrm{l}$. (range 4.4-7.6). Eight paticnts reccived red blood cell transfusions.

Non-haematologic toxicity consisted predominantly of nausea and vomiting in $52 \%$ and alopecia in $48 \%$ of the patients. Diarrhoea and stomatitis were observed in only one patient. Neuropathy was not reported.

\section{DISCUSSION}

VM-26 in a dose of $100 \mathrm{mg} / \mathrm{m}^{2}$ i.v. daily for 2 consecutive days, every 3 weeks, failed to demonstrate any activity in 23 evaluable patients resistant to combination therapy with cisplatin and an alkylating agent. Similar negative results were reported earlier with the use of two different schedules, i.e. $100 \mathrm{mg} / \mathrm{m}^{2}$ day 1 followed by $150 \mathrm{mg} / \mathrm{m}^{2}$ on days 8 and 22 in 20 patients [3] and $30 \mathrm{mg} / \mathrm{m}^{2}$ daily $\times 5$, every $3-4$ weeks, in 16 patients [4]. These studies included only pretreated patients. The results are quite in contrast with those of Jankowski and Vahrson [5] using VM-26 in nonpretreated patients. In the latter study 19 evaluable patients were treated with $150-250 \mathrm{mg} / \mathrm{m}^{2}$ every 10-14 days. The response rate was 58\% (1 CR and 10 PR) with only moderate toxicity.

VM-26 has also been used in combination chemotherapy regimens for advanced ovarian cancer. Do Valle et al. [7] reported a response rate of $70 \%$ (mainly partial responses) in 24 non-pretreated patients using VM-26 in combination with doxorubicin and cyclophosphamide. The contribution of VM-26 to the activity of this combination remains unclear.

Like VP 16-213 [8], VM-26 does not appear to be an active drug when used as second-line treatment. The role of VM-26 as first-line treatment has still to be elucidated.

\section{REFERENCES}

1. Greenspan EM. Ovarian cancer. In: Greenspan EM, ed. Clinical Interpretation and Practice of Cancer Chemotherapy. New York, Raven Press, 1982, 252-263.

2. Neijt JP, ten Bokkel Huinink WW, van der Burg MEL et al. Randomised trial comparing two combination chemotherapy regimens (Hexa-CAF vs CHAP-5) in advanced ovarian carcinoma. Lancet 184, ii, 594-600.

3. Sessa C, D'Incalci M, Landoni F, Colombo N, Mangioni C. Teniposide in refractory ovarian cancer: a phase II study. Cancer Treal Rep 1984, 68, 815-816.

4. Samson MK, Baker LH, Talley RW, Fraile RJ. VM-26 (NSC-122819): a clinical study in advanced cancer of the lung and ovary. Eur J Cancer 1978, 14, 1395-1399.

5. Jankowski RP, Vahrson H. Die Toxizität Hoher Dosen von VM-26 (4-demethyl-epipodophyllotoxin- $\beta$-D-thenylidene glucoside). Med Klin 1977, 72, 2122-2126.

6. WHO Handbook for Reporting Results of Cancer Treatment. WHO Offset Publication No. 48. Geneva, WHO, 1979.

7. Do Valle JC, Sampoia EF de S, Gomes Filho F de A, Soriano JB, Figueredo EM de A, Ribeiro CW. Treatment of advanced ovarian cancer. The results with $\Lambda \mathrm{CV}$ (adriamycin, VM-26 (teniposide) and cyclophosphamide. Rev Bras Cancerol 1983, 29, 3-10.

8. Issell BF. The podophyllotoxin derivatives VP 16-213 and VM-26. Cancer Chemother Pharmacol 1982, 7, 73-80. 